\title{
The use of music to engage children with autism in a receptive labelling task
}

Kate Simpson. Australian Catholic University, PO Box 456 Virginia Queensland 4014, Australia. Email: kmsimp001@myacu.edu.au

*Deb Keen. Education and Professional Studies, Griffith University, 176 Messines Ridge Road, Mt Gravatt, Qld, 4122. E-mail: d.keen@griffith.edu.au

Janeen Lamb. Australian Catholic University, PO Box 456 Virginia Queensland 4014, Australia. Email: Janeen.Lamb@acu.edu.au

Children with autism are less engaged with social and non-social objects and activities than their typically developing peers, resulting in reduced learning opportunities. There is some support for the use of music to enhance the engagement of children with autism but there has been little research investigating the use of music to engage children in language learning tasks and determining if this impacts on learning outcomes. This study investigated the use of music to engage children with autism in a receptive labelling intervention. Twenty two children (mean age 5.9yrs) participated in a randomised controlled cross-over design comparing sung and spoken conditions embedded into a computer based intervention. Child performance and observational data were analysed to determine relationships between music, engagement and learning outcomes. The findings from this research showed children with autism were more engaged in the sung condition compared to the spoken condition although there was considerable variability in levels of engagement between participants. Furthermore, a correlation between engagement and learning was found. Implications of these findings are discussed and recommendations made for future research.

Keywords: Engagement, music, autism, language learning, intervention 


\section{Introduction}

Promoting and supporting engagement for children with Autism Spectrum Disorder (ASD) is viewed as a critical feature of effective learning interventions (Corsello, 2005; National Research Council, 2001). Children with ASD spend less time engaged in social and nonsocial activities than their typically developing peers and children with other developmental disabilities resulting in reduced learning opportunities (Kishida \& Kemp, 2006; McWilliam \& Bailey, 1995; Ruble \& Robson, 2007). Identifying ways to promote engagement has been complicated by the variety of interpretations and definitions of engagement in the research literature. This is possibly due to the multidimensional construct of engagement combining behavioural, emotional and cognitive components (Fredricks, Blumenfeldm, \& Paris, 2004; Keen, 2009). In learning programs, engagement is generally assessed in behavioural terms and refers to an individual's sustained attention or appropriate interaction with people or objects in their environment (Hurth, Shaw, Izeman, Whaley, \& Rogers, 1999; McWilliam \& Bailey, 1995).

Engaging individuals with ASD in learning programs may require deliberate manipulation of materials, activities and the environment. These include the use of activity schedules (Bryan \& Gast, 2000); using motivational variables including the child's interests and preferences (Hurth, et al., 1999; Rispoli et al., 2011) and providing choices (Ulke-Kurkcuoglu \& KircaaliIftar, 2010); and treatment packages incorporating motivational variables (Koegel, Singh, \& Koegel, 2010; Pelios, MacDuff, \& Axelrod, 2003). Despite this there is still a limited understanding of engagement and how this can be promoted in learning tasks for children with ASD.

One way of increasing engagement that has been investigated is the use of music. When provided with auditory stimuli individuals with ASD have shown a preference for music over verbal stimuli (Blackstock, 1978; Buday, 1995). The use of music to target individual goals 
or skills has been classified as an emerging evidence-based practice in the USA National Standards Project (National Autism Center, 2009).

Literature pertaining to the use of music to facilitate engagement in children with ASD has focused predominantly in the area of social-communicative behaviours (Edgerton, 1994; Stephens, 2008; Wimpory, Chadwick, \& Nash, 1995; Wimpory, Hobson, \& Nash, 2007). Interventions have included the use of music to increase peer interactions (Kern \& Aldridge, 2006) and to increase responsivity and the initiation and duration of social engagement between children with ASD and adults (Finnigan \& Starr, 2010; Kim, Wigram, \& Gold, 2009).

Music has also been used in interventions to decrease challenging behaviours that may interfere with learning and to increase task engagement. For example, music has been used effectively with one child with ASD to reduce problem behaviour and increase on task behaviour during stressful situations (Orr, Smith Myles, \& Carlson, 1998). Improvement in on task behaviour has also been achieved by using music as a reinforcer (Gunter \& Fox, 1993). The effectiveness of music as a reinforcer for on task behaviour may, however, be dependent on the characteristics of the task as Gunter and Fox (1993) found task performance improved on vocational but not academic tasks. It may be that academic tasks were considered less desirable than vocational tasks by participants in this study and that music was not sufficiently reinforcing in this context. While music may provide a more engaging learning environment for children with ASD, there has been little research into the use of music to engage children with ASD in language learning activities.

Carnahan and associates incorporated music in a daily small group language arts lesson to investigate engagement in a group of children including five children with ASD, over an eight-week period (Carnahan, Basham, \& Musti-Rao, 2009; Carnahan, Musti-Rao, \& Bailey, 2009). Lessons using interactive books with music led to higher levels of engagement 
compared to interactive books without music. Although engagement increased in the music context the authors did not report whether this impacted on the children's language learning during the activity. Buday (1995) found language learning increased when manual signs were taught in a song compared to a spoken context. Engagement was not measured in this study although the author made a personal observation that task engagement appeared to increase during the song condition. To date, research indicates that music may have the potential to facilitate engagement but no studies have considered the relationship between music, engagement levels and language learning outcomes.

The limited research investigating the use of music to engage children with ASD in interventions to facilitate language acquisition is perhaps surprising considering speech used during infancy is sometimes referred to as 'musical' (Malloch, 1999; Trainor, Clark, Huntley, \& Adams, 1997; Trehub \& Nakata, 2001-2002). Terms such as 'motherese', 'babytalk', or 'infant-directed speech', refer to the particular speech caregivers ubiquitously use with infants characterised by elevated pitch, wider pitch range, shorter and repetitive utterances (Fernald \& Simon, 1984). This speech serves the function of gaining the infant's attention, conveying communicative intent and facilitating language acquisition (Fernald, 1989; Singh, Nestor, Parikh, \& Yull, 2009; Trainor, Austin, \& Desjardins, 2000). Infant-directed speech is more effective in engaging and maintaining the attention of infants than adult-directed speech and this pattern continues into their second year of life (Cooper \& Aslin, 1994; McRoberts, McDonough, \& Lakusta, 2009; Werker \& McLeod, 1989). The affective and prosodic characteristics of infant-directed speech appear to serve an attention getting function (Papoušek, Bornstein, Nuzzo, Papoušek, \& Symmes, 2000; Stern, Spieker, Barnett, \& MacKain, 1983) with the exaggerated pitch aiding speech processing for the prelinguistic listeners (Fernald \& Kuhl, 1987; Fernald \& Mazzie, 1991). These features continue to be used by toddlers to aid in word recognition (Song, Demuth, \& Morgan, 2010). Although 
children with ASD are less responsive to infant-directed speech than their typically developing peers, a relationship between the time children with ASD spend attending to audio presentations of infant-directed speech and their language performance has been reported (Kuhl, Coffey-Corina, Padden, \& Dawson, 2005; Paul, Chawarska, Fowler, Cicchetti, \& Volkmar, 2007). The relationship between attending to infant-directed material and language abilities may be dependent on the development age of the individual. Santarcangelo and Dyer (1988) found teenagers with ASD functioning at a developmental age below 3 yrs were more response to instructions delivered using speech characterised by infant-directed speech prosody compared to conversational speech. These studies raise the question of whether increasing the child's engagement with the affective and prosodic characteristics of infant-directed speech could result in improved language outcomes. Characteristic features of infant-directed speech which include elevated pitch and slower tempo have also been noted in infant-directed song (Fernald, 1989; Trainor, et al., 1997). Infant-directed song as with infant-directed speech also communicates affect and serves a function in regulating the young child's arousal state (Trainor, 1996; Trehub \& Schellenberg, 1995; Trehub, Trainor, \& Unyk, 1993). It would appear that pitch may impact on the infant's level of engagement with his/her external environment. Lullabies serve the purpose of soothing the infant and reducing their focus on the external world and tend to be sung at a lower pitch compared to playsongs that arouse the infant and increase their attention on their external world (Rock, Trainor, \& Addison, 1999; Tsang \& Conrad, 2010). In addition playsongs demonstrate a high rhythmicity highlighting the songs phrase structure (Trainor, 1996). Playsongs may therefore have the potential to increase engagement in learning activities and highlight linguistic structure.

To date there has been no investigation comparing infant-directed song and infant-directed speech on the engagement levels of children with ASD, despite infant-directed song 
sustaining the attention of typically developing infants longer than infant-directed speech (Nakata \& Trehub, 2004). Given the potential for music to engage children with ASD, enhancing the characteristics of infant-directed speech by adding the use of structural musical elements may increase their engagement in a language learning task. The purpose of this study was to investigate whether the use of music during task instruction facilitated engagement of children with ASD and to examine the relationships between music, engagement and learning outcomes.

\section{Materials and method}

\subsection{Participants}

The participants were part of a larger study being conducted by the authors investigating music interventions with children with ASD. Twenty two children with ASD aged between 3 $1 / 2$ years and 9 years (mean age 5.9yrs) completed this study. In addition to a Paediatrician's diagnosis of Autism Spectrum Disorder, the children were assessed using the Social Communication Questionnaire (SCQ; Rutter, Bailey, Berument, Lord, \& Pickles, 2003). All participants met criteria for ASD based on the cut off score of 15 on the SCQ. The Scales of Independent Behaviour Revised (SIB-R; Bruininks, Woodcock, Weatherman, \& Hill, 1996) was used to assess children's adaptive behaviour skills. Scores on this test indicated children required frequent to pervasive support. Class teachers identified children as individuals with limited communication skills, requiring Alternative and Augmentative Communication systems. Additional information about the children's communication skills was gathered using the Expressive Vocabulary Test (EVT-2: Williams, 2007) and Peabody Picture Vocabulary Test (PPVT-4: Dunn \& Dunn, 2007). Only one participant scored above the $1^{\text {st }}$ percentile on expressive language scores and all participants scored below the $1^{\text {st }}$ percentile on receptive language scores. 
This study was conducted with the approval of the State Government Department of Education and Training and the Human Research Ethics Committee of the authors' University. Teacher and parental/guardian permission was obtained prior to the commencement of the study. Children's permission was obtained prior to the commencement of each session using a picture communication symbol.

\subsection{Design}

A cross-over design (Hills \& Armitage, 1979) was used to compare the effect of sung and spoken conditions on participant's engagement and learning during an intervention where they were required to label garden creatures. Children were randomly assigned to one of two groups. Group 1 received the sung intervention condition first followed by the spoken intervention condition while group 2 received the spoken condition first followed by the sung condition. The second intervention condition commenced one month after the cessation of the first intervention condition for both groups.

\subsection{Stimulus materials and setting}

Two sets of comparable materials were developed using vocabulary based on a garden theme and consisted of a contextual sentence, a request to touch a picture, and four creatures (see Table 1). The melody used for the sung condition was "Twinkle, Twinkle". Sung and spoken recordings for each set were made of a female musician performing the materials in the presence of infants to facilitate the emotional expressions observed in infant-directed speech and song (Trainor, 1996; Trainor, et al., 2000). The sets were counterbalanced across the sung and spoken conditions to control for potential order and set effects.

Table 1 goes about here

The lyrics were performed as a playsong. The sung recordings were of ten seconds duration, used a simple quadruple meter and displayed a melodic contour with a specific intervallic rise and fall. In contrast, the spoken recordings were not driven by a sense of meter and were 
delivered slightly faster (seven seconds) displaying a mellifluous contour. The pitch range recorded in the sung and spoken recordings was consistent with the pitch range evident in playsongs and infant-directed speech (McRoberts, et al., 2009; Trainor, et al., 1997). Thus the sung and spoken recordings differed only in the musical elements of melody and rhythm. The creatures were represented using Picture Communication Symbols (PCS) selected from Boardmaker V. 6 (Mayer-Johnson, 2007). The PCS were displayed using a PowerPoint presentation embedded with either the infant-directed sung or the infant-directed spoken recordings. The PowerPoint was displayed on a $40 \mathrm{~cm}$ touch screen monitor which the child activated by using his/her hand or finger. The audio materials were delivered through the computer speakers at normal conversational volume. Each individual session was conducted in a separate room within the participants' school. The participant sat at a table positioned in front of a touch screen monitor. The first author sat beside the participant. The video recorder was positioned on a tripod to the side of the participant to capture the participant's eye gaze.

\subsection{Procedure}

The sung and spoken intervention conditions followed an identical procedure. The intervention consisted of fifteen teaching sessions. During each session the four creatures in the set were randomly named three times. The audio file (contextual sentence, request and creature name) accompanied the picture presentation. The correct picture and two selected pictures from the set were displayed using a three picture horizontal array. Incorrect response or lack of response within a 10 second time period resulted in error correction using a least to most prompt hierarchy (Duker, Didden, \& Sigafoos, 2004). Touching the correct picture (unprompted/prompted) activated the next slide displaying the correct creature PCS and simultaneously presenting the pre-recorded name of the creature. The order of presentation of creatures, the position of the PCS on the screen (left, centre, right) and the selection of the PCS array were randomly assigned across the session. 


\subsection{Recording and coding procedure}

Videotape data was collected for each participant. Duration for each session ranged from 3 6 mins depending on the participants' response time. Videotapes were analysed using 5 second intervals. In addition to occurrences of 'engagement', occurrences of 'challenging behaviour' were also recorded for each 5 second interval for each participant as these behaviours can occur frequently in children with ASD (Georgiades et al., 2011) and can interfere with children's optimal learning and engagement. Engagement was coded if for the duration of the 5 second interval, the child sat on the chair, at the table, looking at the computer screen, and responded to the instruction or prompts and if no challenging behaviours were coded during the interval. An interval was coded as challenging behaviour if, at any time during the 5 second interval, the child left the table; displayed destructive behaviour towards the test materials (e.g. hitting or pushing the screen with force) or aggressive behaviour towards the researcher or themselves (e.g. hitting, biting or scratching); or demonstrated disruptive behaviour described as crying, screaming or non-compliance (not responding to full physical prompt).

Percentage of time engaged for each session was calculated by dividing the number of intervals the participant engaged in the behaviour by the total number of intervals in the session multiplied by 100 . Due to the time required to undertake the detailed analysis and coding of the observational data collected, data from sessions $1,5,10,15$ were selected for analysis. These sessions provided a spread of intervals throughout the period of intervention. Correct responses to the picture labelling task were recorded by the researcher. A response was recorded as correct if, within 10 seconds of giving the instruction, the participant selected the labelled picture unaided. The total number of correct responses for sessions 1, 5, 10 and 15 were recorded and used for analysis.

\subsection{Reliability}


Reliability was conducted on $30 \%$ of the video recordings for each participant in both conditions by a second observer trained in the data recording but blind to the purpose of the study. The video tape segments were randomly selected from the beginning, middle and end of each session and presented in random order to the second observer. The Kappa Measurement of Agreement value on engagement was .75 (occurrence 87\%, nonoccurence $88 \%$ ) representing good agreement; and on challenging behaviour was .85 (occurrence $85 \%$, nonoccurence 91\%) representing very good agreement (Peat, 2001). Only the data recorded by the primary observer were used for data analysis.

\subsection{Data analysis}

Data analysis was designed to compare the effect of the two intervention conditions, sung and spoken, at four time points across the intervention period (Sessions 1,5,10,15), on the level of engagement and behaviour in children with ASD in Group 1 (sung, spoken) and Group 2 (spoken, sung). The analyses, using IBM SPSS Version 20, were as follows:

\subsubsection{A 2x2x4 (Group [1,2] x Condition [sung, spoken] x Time[Sessions 1,5,10,15])}

ANOVA was undertaken to determine whether engagement levels in either of the groups were significantly different for the two intervention conditions across time, and to determine if there was an interaction between order of presentation and condition across time.

2.7.2. Nonparametric tests were used on the behaviour data due to violation of parametric test assumptions of normality identified with the Shapiro-Wilk test. Wilcoxon Signed Rank was conducted to determine the main effect for condition (sung vs spoken); Mann-Whitney $U$ test compared behaviour levels in Group 1 and Group 2; and Friedman tests were conducted on behaviour levels across time in the sung condition, and the spoken condition. 
2.7.3. Pearson's correlation was used to determine the relationship between levels of engagement and correct responses. Spearman Rank Order Correlation was used to determine the relationship between levels of behaviour and correct responses because the data did not meet test assumptions.

\section{Results}

Participants' levels of engagement and behaviour were recorded as percentages of time. The mean $(S D)$ scores for Group 1 and Group 2 in both intervention conditions (sung and spoken) for session 1, session 5, session 10, and session 15, are presented in Table 2. Participant's mean correct response scores and standard deviations are also displayed in Table 2.

\section{Insert Table 2}

\subsection{Comparison of condition, group and time on levels of engagement}

A $2 \times 2 \times 4$ (Condition [sung, spoken] x Group [1, 2] x Time[session 1, 5, 10, 15]) ANOVA was applied to the data in Table 2 to compare participants' level of engagement in the sung and spoken intervention conditions between groups across the intervention period. A significant main effect for condition was obtained $F(1,20)=4.57, p=.04, \eta^{2}=.19$, identifying $19 \%$ of the variance in engagement levels was due to the condition with participants more engaged in the sung compared to the spoken condition. No significant main effect for group was found $F(1,20)=1.79, p=.19$. No significant main effect for time was found $F(1,20)=2.26, p=.09$. There was no significant interaction for group and condition, condition and time, and group, condition, and time. There was however a significant interaction for group and time $p=.003$. For Group 1 there was a decrease in engagement over time while Group 2 displayed fluctuating levels of engagement across the four time periods. In summary, the condition (sung or spoken) had an effect on levels of engagement and there were differences between the groups' level of engagement over the sessions regardless of condition. 


\subsection{Comparison of condition, group and time on levels of challenging behaviour}

The Wilcoxon Signed Rank Test revealed no significant difference in participants' levels of challenging behaviour between the sung and spoken condition $z=-1.84, p=.065, r=.23$. The Mann-Whitney U Test revealed a significant difference in the levels of challenging behaviour of Group $1(M d=10, n=88)$ and Group $2(M d=0.0, n=88), U=2378, z=-$ 4.54, $p<.01$, with a large effect $r=.5$. Freidman Tests were conducted to compare levels of challenging behaviour for Group 1 and Group 2 during sung and spoken conditions across the four time periods. The Friedman Tests showed no significant difference in challenging behaviour across the four time points in the sung condition for Group $1 \chi^{2}(3, n=11)=3.19$, $p=.36$ but a significant difference in challenging behaviour across the four time points in the spoken condition was found $\chi^{2}(3, n=11)=8.57, p=.03$. Further analysis was conducted to identify the difference across time for Group 1 in the spoken condition. Inspection of the median values showed a fluctuating performance in levels of challenging behaviour for Group 1 with an increase from session $1(M d=7)$ to session $5(M d=18)$ followed by a decrease at session $10(M d=5)$ and an increase at session $15(M d=42)$. The Friedman Tests indicated no significant difference in challenging behaviour for Group 2 across the four time points in the sung condition $\chi^{2}(3, n=11)=1.01, p=.80$ or in the spoken condition $\chi^{2}(3, n=$ 11) $=3.42, p=.33$.

\subsection{Correlation between engagement, challenging behaviour and learning}

Important to this study was to investigate the relationship between engagement, challenging behaviour and learning. The relationship between total engagement scores and total correct response scores was investigated using Pearson's correlation coefficient. There was a strong positive correlation between levels of engagement and correct responses in both the sung condition $r(20)=.64, p<.01$, and the spoken condition $r(20)=.71, p<.01$, with high levels of engagement associated with high rates of correct responding. Engagement accounted for 
$41 \%$ of the variance in correct responses in the sung condition and $50 \%$ of the correct responses in the spoken condition.

The relationship between total challenging behaviour scores and total correct response scores was investigated using Spearman Rank Order Correlation. There was no statistically significant correlation between challenging behaviour and correct responses in either the sung $r s(20)=-.41, p=.06$ or spoken condition $r s(20)=-.31, p=.16$.

\section{Discussion}

This study found the use of infant-directed singing was more engaging for children with ASD over infant-directed speech which is consistent with results from research conducted with typically developing children (Nakata \& Trehub, 2004). Furthermore, there was a positive correlation between engagement and learning. Whilst some children were consistently engaged across sessions others showed fluctuations in their levels of engagement across sessions.

Overall, this study found that using musical elements during an intervention to teach language skills to children with ASD enhanced engagement. This supports previous research indicating the use of music may provide a more engaging context for children with autism (Carnahan, Basham, et al., 2009; Carnahan, Musti-Rao, et al., 2009). This study extends previous research by identifying the musical elements which may contribute to promoting an engaging intervention, addressing a limitation identified in previous research on music interventions (review Simpson \& Keen, 2011). The infant-directed song and infant-directed speech used in this study differed in terms of the musical elements of melody and rhythm. In the sung condition the lyrics were set to the melody "Twinkle Twinkle". Several factors about this melody may have contributed to the engagement of the children with ASD who participated. 
"Twinkle Twinkle" is a traditional children's melody and has been used for a number of popular children's songs including "Baa, Baa, Black Sheep" and the "ABC song”. This rhythmic melody displays repetitive musical elements that may be engaging. In addition, participants may have been familiar with the melody through prior exposure and there is some evidence that familiarity may have an impact on levels of engagement (Starr \& Zenker, 1998).

Although there was no overall difference in levels of engagement between the groups, Group 1 displayed a decreasing trend in the levels of engagement from the first to the last session in both conditions. This indicates that as the intervention period progressed the participants in Group 1 became less engaged with the intervention task. Levels of challenging behaviour were also significantly higher in Group 1 compared to Group 2. These findings suggest there may have been underlying differences between the participants in Group 1 and 2 which were not identified in this study, but impacted on the participants' response to the intervention. In addition to differences between participants, levels of engagement may also have been impacted by the sequence order of the intervention conditions. Group 1 (sung/spoken) demonstrated significantly higher levels of challenging behaviour in the spoken condition $\left(2^{\text {nd }}\right.$ condition) associated with a corresponding decrease in levels of engagement. A possible explanation is the levels of challenging behaviour increased when children went from an engaging learning activity (song condition) to a potentially less engaging (spoken condition) learning activity (Koegel, et al., 2010).

Results from this study showed that increased engagement was strongly associated with an increase in correct responding regardless of intervention condition. Both intervention conditions included a computer interface and the use of evidence-based, applied behaviour analysis teaching strategies. It was not the purpose of this study to determine the relative contribution each of these might make to the child's engagement and learning but it would be 
reasonable to assume that the combination was beneficial based on findings from previous research (Moore \& Calvert, 2000; National Autism Center, 2009; Pennington, 2010). In addition, both conditions involved the use of infant-directed stimuli which have been found to be more effective in engaging and maintaining the attention of typically developing infants. This may also be the case for the children with ASD who participated in this study, thereby enhancing levels of engagements and learning. Further research is required to determine if the auditory input in the form of infant-directed speech/song is more beneficial in promoting engagement and accuracy in receptive labelling tasks for children with ASD and severe language delay compared to alternate forms of auditory input.

There were a number of limitations that should be considered when interpreting these results. Although the engagement data demonstrated normality, the small sample size and wide variance across participants suggests caution in generalising these results to the broader population of children with ASD. The wide variance reported highlights the need to consider individual preference as not all children with ASD may find listening to music a positive experience (Devlin, Healy, Leader, \& Reed, 2008).

In addition, this study used a small number of musical elements. The simple melody was sung without instrumental accompaniment. It would be interesting to manipulate musical elements and explore different music genres to better determine which musical features impact on levels of engagement and learning in children with ASD.

A challenge in this type of research is how to define and measure engagement. This study applied a behavioural definition of engagement which may at times have under-estimated engagement levels. For example, during an intervention session, one of the participants was out of his seat and not looking at the computer screen. However, at the auditory prompt to touch the named picture, he returned to the computer made a correct response, and then moved away. In this example, his behaviour while away from the table was coded as 
'challenging behaviour' as it met the definition for this category, but his ability to respond appropriately to the instructions indicates that he was attending in some ways to the task. Furthermore his correct responding took less than five seconds, which was the threshold to define periods of engagement. Similar issues related to defining and measuring engagement have been reported by other researchers (Bagatell, 2012).

In conclusion, while some caution is warranted in generalising these results, this study supports the use of musical elements to facilitate engagement in a language learning task for children with ASD.

\section{Acknowledgements}

This review is part of the first authors' $\mathrm{PhD}$ study and is supported by a $\mathrm{PhD}$ scholarship The Australian Catholic University Postgraduate Award. The authors would like to acknowledge the support of principals, teachers, parents and students from the participating State Special Schools. They would also like to thank Jacqui Cuny for the contribution of her musical skills in the development of the auditory stimuli. 


\section{References}

Bagatell, N. (2012). Engaged moments: Mediated action and children with autism in the classroom setting. OTJR: Occupation, Participation and Health, 32, 258-265. doi: 10.3928/1539449220110722-01

Blackstock, E. G. (1978). Cerebral asymmetry and the development of early infantile autism. Journal of Autism and Childhood Schizophrenia, 8, 339 - 353.

Bruininks, R., Woodcock, R., Weatherman, R., \& Hill, B. (1996). Scales of independent behavior revised comprehensive manual: Riverside Publishing.

Bryan, L. C., \& Gast, D. L. (2000). Teaching on-task and on-schedule behaviors to high-functioning children with autism via picture activity schedules. Journal of Autism and Developmental Disorders, 30, 553-567.

Buday, E. M. (1995). The effects of signed and spoken words taught with music on sign and speech imitation by children with autism. Journal of Music Therapy, 32, 189-202.

Carnahan, C., Basham, J., \& Musti-Rao, S. (2009). A low-technology strategy for increasing engagement of students with autism and significant learning needs. Exceptionality, 17, 7687. doi: $10.1080 / 09362830902805798$

Carnahan, C., Musti-Rao, S., \& Bailey, J. (2009). Promoting active engagement in small group learning experiences for students with autism and significant learning needs. Education \& Treatment of Children, 32, 37-62.

Cooper, R., \& Aslin, R. (1994). Developmental differences in infant attention to the spectral properties of infant-directed speech. Child Development, 65, 1663-1677.

Corsello, C. (2005). Early intervention in autism. Infants and Young Children, 18, 74-85.

Devlin, S., Healy, O., Leader, G., \& Reed, P. (2008). The analysis and treatment of problem behavior evoked by auditory stimulation. Research in Autism Spectrum Disorders, 2, 671-680. doi: 10.1016/j.rasd.2008.02.001

Duker, P., Didden, R., \& Sigafoos, J. (2004). One-to-one training: Instructional procedures for learners with developmental disabilities. Austin, Texas: Pro-ed An International Publisher.

Dunn, L. M., \& Dunn, D. M. (2007). The Peabody Picture Vocabulary Test manual. (4th ed.). Minneapolis: NCS Pearson.

Edgerton, C. L. (1994). The effect of improvisational music therapy on the communicative behaviors of autistic children. Journal of Music Therapy, 31, 31-62.

Fernald, A. (1989). Intonation and communicative intent in mothers' speech to infants: Is the melody the message? Child Development, 60, 1497-1510.

Fernald, A., \& Kuhl, P. (1987). Acoustic determinants of infant preference for motherese speech. Infant Behavior \& Development, 10, 279-293.

Fernald, A., \& Mazzie, C. (1991). Prosody and focus in speech to infants and adults. Developmental Psychology, 27, 209-221.

Fernald, A., \& Simon, T. (1984). Expanded intonation contours in mothers' speech to newborns. Developmental Psychology, 20, $104-113$.

Finnigan, E., \& Starr, E. (2010). Increasing social responsiveness in a child with autism. Autism, 14, 321-348. doi: 10.1177/1362361309357747

Fredricks, J., Blumenfeldm, P., \& Paris, A. (2004). School engagement: Potential of the concept, state of the evidence. Review of Educational Research, 74, 59-109.

Georgiades, S., Szatmari, P., Duku, E., Zwaigenbaum, L., Bryson, S., Roberts, W., . . Pathways in ASD study team. (2011). Phenotypic overlap between core diagnostic features and emotional/behavioral problems in preschool children with autism spectrum disorder. Journal of Autism and Developmental Disorders, 41, 1321-1329. doi: 10.1007/s10803-0101158-9

Gunter, P., \& Fox, J. (1993). A case study of the reduction of aberrant, repetitive responses of an adolescent with autism. Education and Treatment of Children, 16, 187-197. 
Hills, M., \& Armitage, P. (1979). The two-period cross-over clinical trial. British Journal of Clinical Pharmacology, 8, 7-20.

Hurth, J., Shaw, E., Izeman, S., Whaley, K., \& Rogers, S. J. (1999). Areas of agreement about effective practices among programs serving young children with autism spectrum disorders. Infants and Young Children, 12, 17-26.

Keen, D. (2009). Engagement of children with autism in learning. Australasian Journal of Special Education, 33, 130-140. doi: 10.1375/ahse.33.2.130

Kern, P., \& Aldridge, D. (2006). Using embedded music therapy interventions to support outdoor play of young children with autism in an inclusive community-based child care program. Journal of Music Therapy, 43, 270-294.

Kim, J., Wigram, T., \& Gold, C. (2009). Emotional, motivational and interpersonal responsiveness of children with autism in improvisational music therapy. Autism, 13, 389-409. doi: 10.1177/1362361309105660

Kishida, Y., \& Kemp, C. (2006). A measure of engagement for children with intellectual disabilities in early childhood settings: a preliminary study. Journal of Intellectual and Developmental Disability, 31, 101-114. doi: 10.1080/13668250600710823

Koegel, L. K., Singh, A. K., \& Koegel, R. L. (2010). Improving motivation for academics in children with autism. Journal of Autism and Developmental Disorders, 40, 1057-1066. doi: 10.1007/s10803-010-0962-6

Kuhl, P., Coffey-Corina, S., Padden, D., \& Dawson, G. (2005). Links between social and linguistic processing of speech in preschool children with autism: Behavioral and electrophysiological measures. Developmental Science, 8, 1-8.

Malloch, S. (1999). Mothers and infants in communicative musicality. Musicae Scientiae, Special issue 1999-2000, 29-57.

Mayer-Johnson. (2007). Boardmaker, Version 6. Solana Beach, CA: Mayer-Johnson LLC.

McRoberts, G., McDonough, C., \& Lakusta, L. (2009). The role of verbal repetition in the development of infant speech preferences from 4 to 14 months of age. Infancy, 14, 162-194. doi: $10.1080 / 15250000802707062$

McWilliam, R. A., \& Bailey, D. (1995). Effects of classroom social structure and disability on engagement. Topics in Early Childhood Special Education, 15, 123-147.

Moore, M., \& Calvert, S. (2000). Brief report: Vocabulary acquisition for children with autism: Teacher or computer instruction. Journal of Autism and Developmental Disorders, 30, 359362.

Nakata, T., \& Trehub, S. (2004). Infants' responsiveness to maternal speech and singing. Infant Behavior \& Development, 27, 455-464. doi: 10.1016/j.infbeh.2004.03.002

National Autism Center. (2009). National Standards Project: Addressing the need for evidence-based practice guidelines for autism spectrum disorder. Findings and conclusions. Retrieved from http://www.nationalautismcenter.org/pdf/NAC\%20Findings\%20\&\%20Conclusions.pdf

National Research Council. (2001). Educating children with autism. Washington, DC.: National Academy Press.

Orr, T., Smith Myles, B., \& Carlson, J. K. (1998). The impact of rhythmic entrainment on a person with autism. Focus on Autism and other Developmental Disabilities, 13, 163 - 166.

Papoušek, M., Bornstein, M., Nuzzo, C., Papoušek, H., \& Symmes, D. (2000). Infant responses to prototypical melodic contours in parental speech. In D. Muir \& A. Slater (Eds.), Infant development: The essential readings (pp. 261-267). Oxford: Blackwell Publishers.

Paul, R., Chawarska, K., Fowler, C., Cicchetti, D., \& Volkmar, F. (2007). "Listen my children and you shall hear": Auditory preferences in toddlers with autism spectrum disorders. Journal of Speech, Language, and Hearing Research, 50, 1350-1364. doi: 10.1044/10924388(2007/094)

Peat, J. (2001). Health science research: A handbook of quantitative methods. Sydney: Allen \& Unwin. 
Pelios, L., MacDuff, G., \& Axelrod, S. (2003). The effects of a treatment package in establishing independent academic work skills in children with autism. Education and Treatment of Children, 26, 1-21.

Pennington, R. (2010). Computer-assisted instruction for teaching academic skills to students with autism spectrum disorders: A review of literature. Focus on Autism and Other Developmental Disabilities, 25, 239-248. doi: 10.1177/1088357610378291

Rispoli, M., O'Reilly, M., Lang, R., Machalicek, W., Davis, T., \& Sigafoos, J. (2011). Effects of motivating operations on problem and academic behavior in classrooms. Journal of Applied Behavior Analysis, 44, 187-192. doi: 10.1901/jaba.2011.44-187

Rock, A., Trainor, L., \& Addison, T. (1999). Distinctive messages in infant-directed lullabies and play songs. Developmental Psychology, 35, 527-534.

Ruble, L. A., \& Robson, D. M. (2007). Individual and environmental determinants of engagemnt in autism. Journal of Autism and Developmental Disorders, 37, 1457-1468. doi: 10.1007/s10803-006-0222-y

Rutter, M., Bailey, A., Berument, S., Lord, C., \& Pickles, A. (2003). Social communication questionnaire (SCQ). Los Angeles: Western Psychological Services.

Santarcangelo, S., \& Dyer, K. (1988). Prosodic aspects of motherese: Effects on gaze and responsiveness in developmentally disabled children. Journal of Experimental Child Psychology, 46, 406-418.

Simpson, K., \& Keen, D. (2011). Music interventions for children with autism: Narrative review of the literature. Journal of Autism and Developmental Disorders, 41, 1507-1514. doi: 10.1007/s10803-010-1172-y

Singh, L., Nestor, S., Parikh, C., \& Yull, A. (2009). Influences of infant-directed speech on early word recognition. Infancy, 14, 654-666. doi: 10.1080/152500o0903263973

Song, J. Y., Demuth, K., \& Morgan, J. L. (2010). Effects of the acoustic properties of infant-directed speech on infant word recognition. Journal of Acoustical Society of America, 128, 389-400. doi: $10.1121 / 1.3419786$

Starr, E., \& Zenker, K. (1998). Understanding autism in the context of music therapy: Bridging theory and practice. Canadian Journal of Music Therapy, 6, 1-19.

Stephens, C. (2008). Spontaneous imitation by children with autism during a repetitive musical play routine. Autism, 12, 645-671. doi: 10.1177/1362361308097117

Stern, D., Spieker, S., Barnett, R., \& MacKain, K. (1983). The prosody of maternal speech: Infant age and context related changes. Journal of Child Language, 10, 1-15.

Trainor, L. (1996). Infant preferences for infant-directed versus non-infant-directed playsongs and lullabies. Infant Behavior \& Development, 19, 83-92.

Trainor, L., Austin, C., \& Desjardins, R. (2000). Is infant-directed speech prosody a result of vocal expression of emotion? Psychological Science, 11, 188-195.

Trainor, L., Clark, E., Huntley, A., \& Adams, B. (1997). The acoustic basis of preferences for infantdirected singing. Infant Behavior \& Development, 20, 383-396.

Trehub, S., \& Nakata, T. (2001-2002). Emotion and music in infancy. Musicae Scientiae, Spec Issue 2001-2002, 37-61.

Trehub, S., \& Schellenberg, E. (1995). Music: Its relevance to infants. In R. Vasta (Ed.), Annals of Child Development (Vol. 11, pp. 1-24). New York: Jessica Kingsley.

Trehub, S., Trainor, L., \& Unyk, A. (1993). Music and speech processing in the first year of life. Advances in Child Development, 24, 1-35.

Tsang, C., \& Conrad, N. (2010). Does the message matter? The effect of song type on infants' pitch preferences for lullabies and playsongs. Infant Behavior \& Development, 33, 96-100. doi: 10.1016/j.infbeh.2009.11.006

Ulke-Kurkcuoglu, B., \& Kircaali-Iftar, G. (2010). A comparison of the effects of providing activity and material choice to children with autism specturm disorders. Journal of Applied Behavior Analysis, 43, 717-721. doi: 10.1901/jaba.2010.43-717 
Werker, J., \& McLeod, P. (1989). Infant preference for both male and female infant-directed talk: A developmental study of attentional and affective responsiveness. Canadian Journal of Psychology, 43, 230-246.

Williams, K. T. (2007). Expressive vocabulary test (2nd ed.). Minneapolis, MN: NCS Pearson, Inc.

Wimpory, D., Chadwick, P., \& Nash, S. (1995). Brief report: Musical interaction therapy for children with autism: An evaluative case study with two-year follow-up. Journal of Autism and Developmental Disorders, 25, 541-552.

Wimpory, D., Hobson, R., \& Nash, S. (2007). What facilitates social engagement in autism? Journal of Autism and Developmental Disorders, 37, 564-573. 
Table 1

Material Sets

\begin{tabular}{llll}
\hline Set & Contextual sentence & Instruction & Creatures \\
\hline 1 & $\begin{array}{l}\text { In my garden come and find the little } \\
\text { creature that I say. }\end{array}$ & Touch the ... & $\begin{array}{l}\text { Daddylonglegs, Dragonfly, } \\
\text { Stinkbug, Slug }\end{array}$ \\
2 & $\begin{array}{l}\text { Little creatures everywhere can you } \\
\text { find the one I say? }\end{array}$ & Touch the ... & $\begin{array}{l}\text { Prayingmantis, Cockatoo, } \\
\text { Gecko, Wasp }\end{array}$ \\
\hline
\end{tabular}


Table 2

Levels of Engagement, Challenging Behaviour and Correct Responses

\begin{tabular}{|c|c|c|c|c|c|c|c|c|}
\hline & \multicolumn{4}{|c|}{ Sung condition } & \multicolumn{4}{|c|}{ Spoken condition } \\
\hline & Session 1 & Session 5 & Session 10 & Session 15 & Session 1 & Session 5 & Session 10 & Session 15 \\
\hline \multicolumn{9}{|l|}{ Group 1} \\
\hline & $63.18(17.05)$ & $59.91(25.72)$ & $38.18(18.51)$ & $43.18(26.42)$ & $39.36(19.81)$ & $38.36(23.48)$ & $39.36(23.15)$ & $28.55(22.25)$ \\
\hline \multicolumn{9}{|l|}{ Engagement } \\
\hline Behaviour & $7.55(4.61)$ & $11.18(20.15)$ & $17.73(20.32)$ & $24.27(27.18)$ & $16.91(17.80)$ & $30.00(27.16)$ & $15.36(17.89)$ & $40.55(36.99)$ \\
\hline Receptive & $3.55(1.97)$ & $4.18(3.34)$ & $4.09(2.74)$ & $3.36(3.50)$ & $3.27(2.57)$ & $2.18(1.60)$ & $2.27(1.95)$ & $2.55(2.77)$ \\
\hline \multicolumn{9}{|l|}{ Group 2} \\
\hline & $46.82(23.54)$ & $55.45(16.67)$ & $54.91(26.45)$ & $59.27(22.81)$ & $46.36(19.04)$ & $56.55(28.55)$ & $46.55(26.35)$ & $53.45(22.02)$ \\
\hline \multicolumn{9}{|l|}{ Engagement } \\
\hline Behaviour & $17.82(26.20)$ & $5.82(9.55)$ & $6.91(12.24)$ & 7.82(11.86) & $9.09(19.06)$ & $7.27(8.39)$ & $10.00(21.15)$ & $9.91(19.46)$ \\
\hline Receptive & $3.82(4.09)$ & $6.09(4.66)$ & $6.73(4.80)$ & $6.27(5.42)$ & $4.55(2.98)$ & $6.18(3.63)$ & $5.73(4.32)$ & $6.45(4.03)$ \\
\hline
\end{tabular}

